\title{
Flagella-Driven Chemotaxis Towards Exudate Components Is an Important Trait for Tomato Root Colonization by Pseudomonas fluorescens
}

\author{
Sandra de Weert, ${ }^{1}$ Hans Vermeiren, ${ }^{2}$ Ine H.M. Mulders, ${ }^{1}$ Irene Kuiper, ${ }^{1}$ Nico Hendrickx, ${ }^{2}$ Guido V. \\ Bloemberg, ${ }^{1}$ Jos Vanderleyden, ${ }^{2}$ René De Mot, ${ }^{2}$ and Ben J.J. Lugtenberg ${ }^{1}$ \\ ${ }^{1}$ Leiden University, Institute of Molecular Plant Sciences, Wassenaarseweg 64, 2333 AL Leiden, The Netherlands; \\ ${ }^{2}$ Catholic University of Leuven, Centre of Microbial and Plant Genetics, Kasteelpark Arenberg 20, B-3001 Heverlee, \\ Belgium
}

Submitted 9 May 2002. Accepted 17 July 2002.

Motility is a major trait for competitive tomato root-tip colonization by Pseudomonas fluorescens. To test the hypothesis that this role of motility is based on chemotaxis toward exudate components, cheA mutants that were defective in flagella-driven chemotaxis but retained motility were constructed in four $P$. fluorescens strains. After inoculation of seedlings with a 1:1 mixture of wild-type and nonmotile mutants all mutants had a strongly reduced competitive root colonizing ability after 7 days of plant growth, both in a gnotobiotic sand system as well as in nonsterile potting soil. The differences were significant on all root parts and increased from root base to root tip. Significant differences at the root tip could already be detected after 2 to 3 days. These experiments show that chemotaxis is an important competitive colonization trait. The best competitive root-tip colonizer, strain WCS365, was tested for chemotaxis toward tomato root exudate and its major identified components. A chemotactic response was detected toward root exudate, some organic acids, and some amino acids from this exudate but not toward its sugars. Comparison of the minimal concentrations required for a chemotactic response with concentrations estimated for exudates suggested that malic acid and citric acid are among major chemo-attractants for P. fluorescens WCS365 cells in the tomato rhizosphere.

It is evident that colonization of at least part of the root system is required for the beneficial effects of inoculant bacteria for applications such as biocontrol of soil-borne diseases (Bull et al. 1991; Chin-A-Woeng et al. 2000; Lugtenberg et al. 1991; Schippers et al. 1987; Suslow and Schroth 1981; Weller and Thomashow 1994), biofertilization, and phytostimulation (Okon et al. 1998) and phytoremediation (Kuiper et al. 2001). To obtain a better understanding of the mechanism behind competitive tomato root-tip colonization, traits were identified that are required for efficient competitive root colonization, a topic which has recently been reviewed by Lugtenberg and associates (2001). One of these traits is motility. Although Howie and associates (1987) and Scher and associates (1988) reported that nonmotile mutants of fluorescent pseudomonads on wheat and of Pseudomonas and Serratia species on soybean are not impaired in root colonization, nonmotile mutants of $P$. fluorescens WCS374 (de Weger et

Corresponding author: S. de Weert, Telephone: +31 715275072, Fax: +31 5275088, E-mail: weert@ rulbim.leidenuniv.nl al. 1987), P. fluorescens WCS365 (Dekkers et al. 1998b; Simons et al. 1996), and $P$. putida WCS358 (Simons et al. 1996) show a clear defect in competitive root-tip colonization of potato, wheat, radish, and tomato. Although the differences between the results of Howie and associates (1987) and Scher and associates (1988) with the results found in our group can be due to different assays, plants, and experimental conditions, it should be emphasized that, in our tests, nonmotile mutants belong to the most defective class of competitive root-tip colonization mutants (Lugtenberg et al. 2001). Since it seems reasonable to hypothesize that the role of motility in root colonization is to reach the nutrients exuded by the roots (Lugtenberg et al. 1999; Simons et al. 1997; A. H. M. Wijfjes, unpublished data), we decided to investigate whether the best competitive tomato root-tip colonizer we have tested so far, strain P. fluorescens WCS365 (Dekkers et al. 1998a; Geels and Schippers 1983) shows chemotactic behavior toward tomato root exudate and, if so, to its individual exudate components. To this end, we constructed mutants in the cheA gene, which controls flagella-driven chemotaxis. Furthermore, P. fluorescens WCS365 appeared to show chemotaxis toward root exudate as well as toward some individual exudate components. We show that chemotaxis plays a major role in competitive tomato root-tip colonization.

\section{RESULTS}

Characterization of cheA mutants

of various $P$. fluorescens strains.

cheA mutants were generated from the four different $P$. fluorescens wild-type strains OE28.3, SBW25, F113, and WCS365 and were designated as FAJ2061, FAJ0761, FAJ0758, and FAJ2060, respectively (Table 1). No effect of the cheA mutation on growth rate in King's medium $B(\mathrm{~KB})$ medium was observed, neither when strains were tested individually nor when tested in competition (data not shown). Microscopic image analysis of these cheA mutants revealed that they remain motile but have a much lower tumbling frequency compared with the wild-type cells. Movies showing the swimming behavior of the wild-type strains and the corresponding cheA mutants can be viewed on the Catholic University of Leuven Agricultural and Applied Biological Sciences Faculty PGPR and biodegradation web page.

Swarming assays conducted on a semisolid minimal basic medium (BM)-succinic acid plates revealed that wild-type WCS365, its cheA mutant FAJ2060, and its nonmotile mutant PCL1524 had ring diameters of $26 \pm 2,8 \pm 1$, and $2 \pm 1 \mathrm{~mm}$, 
respectively (Fig. 1). Since PCL1524 in contrast to FAJ2060 is unable to swim, the ring formed by the latter strain is the result of smooth swimming. Similar differences between wild-type and cheA mutants were obtained for the other three strains. Assays on semisolid $\mathrm{KB}$ plates gave results similar to those in Figure 1.

\section{Effect of cheA mutations on tomato root colonization in sand and soil systems.}

The colonizing behavior of chemotatic mutants and their wild-type strains was initially analyzed using the gnotobiotic sand system described by Simons and associates (1996). The single homologous cheA mutants, FAJ2061 and FAJ2060, of OE28.3 and WCS365, respectively, appeared to be $100 \%$ stable in the rhizosphere, as judged after testing for the presence of antibiotic-resistant isolates released from the roots. Colonization assays in sand with wild-type strains or cheA mutants inoculated alone on a seedling show that cheA mutants colonize the root tip to the same extent as wild-type strains (data not shown). When tested in the gnotobiotic system in competition with their wild type after inoculation of seedlings with a $1: 1$ mixture, all cheA mutants show a 10 - to 1000 -fold reduced ability to colonize the root tip of tomato (Table 2). Isolation of attached bacteria immediately after inoculation of the seedlings confirmed that, for all strains, the ratio of wild type and mutants on the seedling was indeed 1:1, as in the inoculation mixture.

Colonization assays in nonsterile potting soil (Table 3) showed that CFU values in soil of both mutant and wild-type strains are about 100-fold less when compared with the CFU values obtained in sand (Table 2). After applying the cheA mutants or the wild-type strains alone on the seedling, an at least 100-fold impaired root-tip colonization phenotype was observed in potting soil for the cheA mutants when compared with the wild-type strains (data not shown). Competitive root-tip colonization assays in soil on tomato show an approximately 10-fold impaired colonization ability for the cheA mutants (Table 3 ).

A time-course experiment of competitive root-tip colonization in the gnotobiotic sand system analyzed for four days showed that the cheA mutants are already significantly outcompeted after 2 to 3 days (Table 4 ).

In order to gain insight into the distribution of bacteria along the root, competitive colonization assays were performed with WCS365 and its cheA mutant FAJ2060 on tomato in sand as well as in soil. The roots were divided into four parts: $1 \mathrm{~cm}$ just underneath the crown, the middle part of the root divided into two parts with an equal length of approximately 3 to $4 \mathrm{~cm}$, and the root tip $(1 \mathrm{~cm})$. After 7 days of plant growth in sand (Table 5) or nonsterile soil (data not shown), the cheA mutant appeared to be present in significantly decreased numbers on the upper part of the root (Table 5), whereas it could hardly be detected on the root tip. The latter results confirm the results of our previous competition experiments (Tables 2 and 3).

\section{Chemotaxis toward tomato root exudate and individual exudate components.}

Since $P$. fluorescens strain WCS365 is the best competitive tomato root-tip colonizer of the four studied strains, this strain, its cheA mutant FAJ2060, and its nonmotile mutant PCL1524 were used to study the putative role of chemotaxis toward tomato root exudate in the drop assay of Fahrner and associates (1994) as described by Grimm and Harwood (1997). Concentrated (50-fold) tomato root exudate as well as individual exudate components were tested (Fig. 2 and Table 6). In contrast to the control with chemotaxis buffer (Fig. 2A), concentrated root exudate, as well as several individual organic acids including succinic acid (Fig. 2B) and malic acid (Fig. 2C), initiated a clear response of the WCS365 cells (Table 6). Neither the other tested organic acids nor exudate sugars induced a response (Table 6). The dominant amino acids present in the tomato root exudate, L-aspartic acid, L-glutamic acid, L-isoleucine, L-leucine, and L-lysine (Simons et al. 1997) all induced a response from WCS365 cells when tested in $10-\mu \mathrm{l}$ drops at concentrations of $100 \mathrm{mM}$

Various concentrations of organic acids and amino acids were tested in $10-\mu \mathrm{l}$ drops to determine the threshold concentration that was able to induce chemotaxis. For citric acid, malic acid, fumaric acid, and pyroglutamic acid, concentrations as low as 10 to $20 \mathrm{mM}$ initiated a response. For succinic acid, a $40 \mathrm{mM}$ concentration initiated a significant response of the cells (Fig. 2). Four out of five major amino acids, L-aspartic acid, L-glutamic acid, L-isoleucine, and L-leucine (Table 6), initiated a response at concentrations of about $10 \mathrm{mM}$ or lower. For L-lysine, a $20 \mathrm{mM}$ concentration induced chemotaxis of the WCS365 cells. The responses toward these amino acids were faster (shorter incubation time) and stronger (lower concentrations detectable) than toward organic acids tested at $10 \mathrm{mM}$.

Table 1. Bacterial strains and plasmids used in this study

\begin{tabular}{|c|c|c|}
\hline $\begin{array}{l}\text { Strains and } \\
\text { plasmids }\end{array}$ & Relevant characteristics & Reference or Source \\
\hline \multicolumn{3}{|c|}{ Pseudomonas fluorescens } \\
\hline WCS365 & Wild-type biocontrol strain, efficient competitive colonizer of tomato, potato, and wheat roots & Dekkers et al. $1998 \mathrm{a}$ \\
\hline & & Geels and Schippers 1983 \\
\hline PCL1500 & Tn5lacZ derivative of WCS365, not impaired in competitive root colonization, $\mathrm{Km}^{\mathrm{r}}$ & van der Bij et al. 1996 \\
\hline FAJ2060 & WCS365 mutant with an impaired cheA gene constructed by single homologous recombination, $\mathrm{Km}^{\mathrm{r}}$ & This study \\
\hline F113 & Wild-type biocontrol strain & Shanahan et al. 1992 \\
\hline PCL1510 & Tn5lacZ derivative of F113, not impaired in competitive root-tip colonization, $\mathrm{Km}^{\mathrm{r}}$ & This study \\
\hline FAJ0758 & F113 mutant with an impaired $c h e A$ gene after double homologous recombination, $\mathrm{Km}^{\mathrm{r}}$ & This study \\
\hline SBW25 & Wild-type biocontrol strain & Rainey and Bailey 1996 \\
\hline FAJ0761 & SBW25 mutant with an impaired cheA gene constructed by double homologous recombination, $\mathrm{Km}^{\mathrm{r}}$ & This study \\
\hline OE28.3 & Wild-type strain, colonizer of wheat roots & De Mot and Vanderleyden 1991 \\
\hline PCL1513 & Tn5lacZ derivative of OE28.3, not impaired in competitive root-tip colonization & This study \\
\hline FAJ2061 & OE28.3 mutant with an impaired cheA gene constructed by single homologous recombination, $\mathrm{Km}^{\mathrm{r}}$ & This study \\
\hline PCL1524 & Tn5 derivative of $P$. fluorescens WCS365, lacking flagella & Camacho 2001 \\
\hline \multicolumn{3}{|c|}{ Escherichia coli } \\
\hline S17-1 & MM294, RP4-2 Tc::Mu-Km::Tn7 chromosomally integrated & Simon et al. 1983 \\
\hline \multicolumn{3}{|c|}{ the } \\
\hline pCIB 100 & $\begin{array}{l}\text { pLRKA211 (ColE1) with pSUP5011 mobilization segment. Carries Tn5lacZ }\left(\mathrm{Km}^{\mathrm{r}}\right) \text {. The } \operatorname{lacZ} \text { is } \\
\text { constitutively expressed in Pseudomonas spp. }\end{array}$ & Lam et al. 1990 \\
\hline pCR2.1 & Cloning vector for Taq-amplified PCR products, $\mathrm{Km}^{\mathrm{r}}, \mathrm{Ap}^{\mathrm{r}}$ & Invitrogen \\
\hline pSUP202 & Mobilizable pBR325 derivative, $\mathrm{Tc}^{\mathrm{r}}, \mathrm{Cm}^{\mathrm{r}}, \mathrm{Ap}^{\mathrm{r}}$ & Simon et al. 1983 \\
\hline pUC4K & pUC4 derivative with aminoglycoside $3^{\prime}$-phosphotransferase gene $(a p h)$ from $\mathrm{Tn} 903, \mathrm{Km}^{\mathrm{r}}$ & Amersham Pharmacia Biotech \\
\hline
\end{tabular}


Also the other amino acids found in the tomato root exudates, namely L-histidine, L-phenylalanine, glycine, L-arginine, Lthreonine, L -asparagine, and L-glutamine, initiated a response at concentrations as low as $10 \mathrm{mM}$, except L-phenylalanine, which initiated no response at all.

\section{DISCUSSION}

\section{Characterization of cheA mutants of various $\boldsymbol{P}$. fluorescens strains.}

We have shown previously that motility is an important trait for competitive tomato root-tip colonization (Dekkers et al. 1998b; de Weger et al. 1987, 1997; Simons et al. 1996). To test the hypothesis that chemotaxis toward root exudate components is the reason behind this phenomenon, we disrupted the cheA gene controlling flagella-mediated swimming toward chemo-attractants in four root-colonizing $P$. fluorescens strains (Fig. 3) and tested their colonizing (Tables 2 through 5) and chemotactic (Fig. 2; Table 6) behavior.

Chemotaxis is mediated by a two-component regulatory system consisting of a sensor kinase, $\mathrm{CheA}$, and a response regulator, CheY. Chemoreceptors, methyl-accepting proteins (MCPs), are transmembrane signal transducers located in the cytoplasmic membrane. They monitor the concentration of the corresponding chemicals in the environment. Via methylation of the MCPs, a signal is transduced, and autophosphorylation of CheA takes place. Subsequently, P-CheA donates the phosphate group to $\mathrm{CheY}$, and $\mathrm{P}-\mathrm{CheY}$ will interact with the flagellar motor. Whenever the signal drops below a certain threshold, CheY will be phosphorylated, and clockwise rotation will oc-

Table 2. Competitive tomato root-tip colonization ability of cheA mutants of four Pseudomonas fluorescens strains ${ }^{\mathrm{y}}$

\begin{tabular}{lcc}
\hline & \multicolumn{2}{c}{$\begin{array}{c}\text { Competitive root-tip colonization } \\
{\left[\log _{10}(\mathbf{C F U}+\mathbf{1} / \mathbf{c m}) \text { root tip] }^{\mathbf{z}}\right.}\end{array}$} \\
\cline { 2 - 3 } Competing strains & Wild type & cheA mutant \\
\hline WCS365 vs. FAJ2060 & $4.8 \pm 0.9 \mathrm{a}$ & $1.9 \pm 1.7 \mathrm{~b}$ \\
OE28.3 vs. FAJ2061 & $4.7 \pm 1.8 \mathrm{a}$ & $3.6 \pm 2.4 \mathrm{~b}$ \\
SBW25 vs. FAJ0761 & $4.9 \pm 0.5 \mathrm{a}$ & $2.9 \pm 1.2 \mathrm{~b}$ \\
F113 vs. FAJ0758 & $5.1 \pm 0.9 \mathrm{a}$ & $2.2 \pm 1.9 \mathrm{~b}$ \\
\hline
\end{tabular}

${ }^{\mathrm{y}}$ Strains were tested in a gnotobiotic sand system. Mutant strains were inoculated on seedlings in a 1:1 ratio with the wild-type strain. Plant roots were analyzed after 7 days.

${ }^{\mathrm{z}}$ In every experiment, 10 plants were inoculated and individually processed. When values in the same row are followed by a different letter, they are significantly different at $P=0.05$ on nonparametric multiple comparisons using the Wilcoxon-Mann-Whitney test. X-gal was added for plate selection. cur. Subsequently, the bacteria will start to tumble, which is required to change swimming direction (Adler 1969; Aizawa et al. 2000). If this signal rises above the threshold value, CheY will be dephosphorylated and counter clockwise rotation will occur, resulting in a run of the bacterial cell.

In the cheA-containing motility and chemotaxis region on the chromosome of both P. putida PRS2000 (Ditty et al. 1998) and $P$. aeruginosa PAO1 (Kato et al. 1999), two putative motility genes ( $m o t A$ and $\operatorname{mot} B$, encoding components of the protondriven flagellar motor) are present downstream of $c h e B$. From the high organizational conservation of this DNA region among Pseudomonas species and from analysis of the corresponding gene cluster in $P$. fluorescens PfO-1, the gene order cheA-cheB-motA-motB can be expected for the P. fluorescens strains used in this study. We have identified an equivalent locus in $P$. fluorescens OE28.3 (GenBank accession number AF481091) (Fig. 3), and in silico analysis revealed it to be highly conserved in $P$. fluorescens $\mathrm{PfO}-1, P$. syringae pv. syringae DC3000, and P. putida KT2440 as well.

The cheA gene targeted in this study directs flagella-mediated swimming toward chemo-attractants. Genome analysis has revealed the coexistence of multiple chemosensory systems in Pseudomonas spp. P. aeruginosa PAO1 has three additional loci with che-like genes that encode (probable) chemosensory pathways (Stover et al. 2000). One of these loci is required for type IV pili-mediated twitching motility (Darzins 1994; Kearns et al. 2001), and similar loci can be found in the draft genomic sequences of $P$. fluorescens $\mathrm{PfO}-1, P$. syringae DC3000, and $P$. putida KT2440. No function has yet been assigned to the two other putative chemosensory systems (Bourret et al. 2002). Locus PA3708-PA3702 of $P$. aeruginosa PAO1 is highly conserved in $P$. fluorescens PfO-1, P. syringae DC3000, and $P$. putida KT2440 and has an equivalent in $P$. fluorescens OE28.3 as well (R. De Mot, unpublished data). A counterpart for the second uncharacterized $P$. aeruginosa locus, PA0180-PA0173, appears to be absent from these fluorescent Pseudomonas spp.

Since the constructed mutants can only be used to test our hypothesis when the cheA mutations have no effect on (putative) downstream motility genes, we studied their motility using microscopic video analysis. The results indicate that the cheA mutants are motile but impaired in chemotaxis because of the lower tumbling frequency. In addition, using swim plate assays, it was shown for $P$. fluoresens WCS365 that its cheA mutant FAJ2060 is motile, in contrast to its nonmotile mutant, PCL1524 (Fig. 1). In conclusion, the cheA mutations in the constructed cheA mutants do not affect motility. Smooth swimming behavior is expected for cells that do not phosphorylate $\mathrm{CheY}$ due to a defective CheA protein, as was ob-
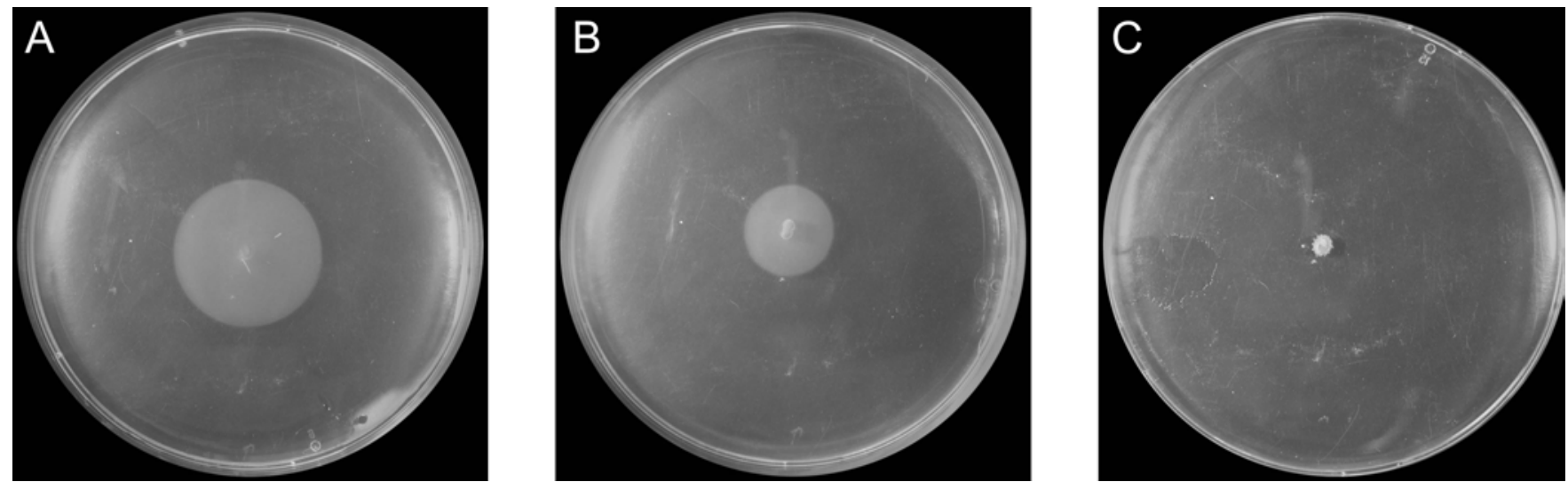

Fig. 1. Motility assay on minimal basic medium. Medium was solidified with $0.3 \%$ agar and succinic acid $(0.01 \%)$ added as a carbon source. The plates were inoculated with A, Pseudomonas fluorescens WCS365; B, its cheA mutant FAJ2060; and C, its nonmotile mutant PCL1524. 
served previously for cheA mutants of $P$. putida (Ditty et al. 1998) and $P$. aeruginosa (Kato et al. 1999).

\section{Effect of cheA mutations on tomato root colonization.}

To study the behavior of the cheA mutants in the rhizosphere of tomato, seedlings were inoculated with a 1:1 mixture of the parental strain and the respective mutant or with a suspension of each strain alone and allowed to grow in a gnotobiotic sand system or in nonsterile potting soil. Although the cheA mutants are not impaired in their colonizing ability of tomato roots in sand after inoculation alone on the seedlings (data not shown), all cheA mutants appeared to be heavily impaired in their competitive colonization behavior under gnotobiotic conditions (Table 2) as well as in potting soil (Table 3). It should be noted that, in the latter case, a large (approximately $10^{8} \mathrm{CFU} / \mathrm{g}$ ) indigenous microbial population was present. The ability of colonization mutants to colonize root tips to the same extent as the parental strain after inoculation alone was observed earlier for most colonization defective mutants (Lugtenberg et al. 2001). In order to further compare the behavior of $c h e A$ mutants during competitive root colonization with that of the parental strain, we followed colonization through time for all four strains and their corresponding cheA mutants (Table 4) and spatial distribution along the colonized roots (Table 5) for $P$. fluorescens strain WCS365 and its cheA mutant, FAJ2060. A time-course of colonization showed that, 2 to 3 days after the root system starts to develop when root systems are still short, the mutants are losing the competition (Table 4). Apparently as soon as the root starts to develop, cheA mutants in contrast to wild-type cells are not able to keep track of the growing root under competitive conditions.

Analysis of the spatial distribution of bacteria along the root during competitive colonization showed that, after 7 days of growth, the cheA mutant FAJ2060 is present, although in much lower cell numbers, on the upper and middle parts of the roots, whereas it is hardly detectable on the root tip (Table 5). These results indicate that decreased abilities of cheA mutants for proliferation, survival, or both on higher root parts are responsible for their poor competitive root-tip colonization. The poor chemotactic ability of cheA mutants toward major root exudate components (discussed below) is the likely reason for this defect.

\section{Chemotaxis toward tomato root exudate and its individual components.}

Since $P$. fluorescens WCS365 is the best competitive root-tip colonizer of the tested strains, this strain, its cheA mutant FAJ2060, and its nonmotile mutant PCL1524 were used in the chemotaxis drop assay of Fahrner and associates (1994) also described by Grimm and Harwood (1997). This drop assay was used to analyze taxis toward tomato root exudate as well as

Table 3. Competitive tomato root tip colonization ability of cheA mutants of four Pseudomonas fluorescens strain in nonsterile potting soil ${ }^{y}$

\begin{tabular}{llc}
\hline & \multicolumn{2}{c}{$\begin{array}{c}\text { Competitive root-tip colonization } \\
{\left[\log _{\mathbf{1 0}}(\mathbf{C F U}+\mathbf{1} / \mathbf{c m}) \text { root tip] }\right]^{\mathbf{z}}}\end{array}$} \\
\cline { 2 - 3 } Competing strains & Wild type & cheA mutant \\
\hline WCS365 vs.FAJ2060 & $2.9 \pm 1.6 \mathrm{a}$ & $1.9 \pm 1.3 \mathrm{~b}$ \\
OE28.3 vs. FAJ2061 & $2.6 \pm 1.9 \mathrm{a}$ & $2.0 \pm 1.3 \mathrm{~b}$ \\
SBW25 vs. FAJ0761 & $3.5 \pm 0.5 \mathrm{a}$ & $2.5 \pm 2.2 \mathrm{~b}$ \\
F113 vs. FAJ0758 & $2.8 \pm 1.6 \mathrm{a}$ & $1.6 \pm 1.4 \mathrm{~b}$
\end{tabular}

${ }^{\mathrm{y}}$ Mutant strains are inoculated on seedlings in a 1:1 ratio with the wildtype strain. Plant roots were analyzed after 7 days.

${ }^{\mathrm{z}}$ In every experiment, 10 plants were inoculated and individually processed. When values in the same row are followed by a different letter, they are significantly different at $P=0.05$ on nonparametric multiple comparisons using the Wilcoxon-Mann-Whitney test. toward the known individual components of the tomato root and seedling exudate (Table 6).

Previous studies on tomato exudate have shown that its major components are organic acids (with citric [55.2\%], malic [15.3\%], and lactic [10\%] acids as the major components) (A. H. M. Wijfjes, unpublished data), amino acids (especially isoleucine, leucine, lysine, aspartic acid, and glutamic acid) (Simons et al., 1997; A. H. Wijfjes et al., unpublished data), and sugars (with glucose [37\%] and xylose [33\%] as major components) (Lugtenberg et al. 1999). In our chemotaxis study, 5 out of 10 organic acids and all major amino acids but none of the sugars initiated a response of WCS365 cells (Table 6). Nonmotile mutants, cheA mutants, and the chemotaxis buffer (control) did not initiate a response. In order to identify the best chemo-attractant, various concentrations of the individual components (filter sterile) in a 4- to $100-\mathrm{mM}$ range were tested. Results show that, among the organic acids, only malic acid could be detected by WCS365 cells at $10 \mathrm{mM}$. At this concentration, all amino acids except L-lysine were detected. Lisoleucine appeared to be the best chemo-attractant (Table 6) since its minimal concentration for detection $(4 \mathrm{mM})$ was 2.5 fold lower than that for malic acid. When we compare the concentration-dependent chemotactic responses of cells to malic acid and L-isoleucine (with their concentrations in the exudate being approximately 70 and $2.2 \mu \mathrm{M}$, respectively), we can suggest that malic acid is one of the most important chemo-attractants in the tomato rhizosphere. In addition, we suggest that citric acid, present in the exudate at approximately $115 \mu \mathrm{M}$ and active as a chemo-attractant in a concentration as low as 20 $\mathrm{mM}$, represents another major chemo-attractant in this rhizosphere.

\section{MATERIALS AND METHODS}

Bacterial strains and growth conditions.

All P. fluorescens strains and their chemotatic mutants (Table 1) were grown in liquid $\mathrm{KB}$ (King et al. 1954) at $28^{\circ} \mathrm{C}$

Table 4. Time-course of competitive tomato-root-tip colonization of cheA mutants of four Pseudomonas fluorescens strains ${ }^{\mathrm{y}}$

\begin{tabular}{|c|c|c|}
\hline \multirow[b]{2}{*}{ Competing strains } & \multicolumn{2}{|c|}{$\begin{array}{c}\text { Competitive root-tip colonization } \\
{\left[\log _{10}(\mathrm{CFU}+1 / \mathrm{cm}) \text { root tip }\right]}\end{array}$} \\
\hline & Wild type & cheA mutant \\
\hline \multicolumn{3}{|l|}{ WCS365 vs. FAJ 2060} \\
\hline Day 1 & $5.3 \pm 0.1 \mathrm{a}$ & $5.2 \pm 0.1 b$ \\
\hline Day 2 & $5.2 \pm 0.2 \mathrm{a}$ & $4.9 \pm 0.2 b$ \\
\hline Day 3 & $5.6 \pm 0.0 \mathrm{a}$ & $4.5 \pm 0.3 b$ \\
\hline Day 4 & $5.4 \pm 0.3 a$ & $3.3 \pm 0.6 b$ \\
\hline \multicolumn{3}{|l|}{ OE28.3 vs. FAJ2061 } \\
\hline Day 1 & $5.8 \pm 0.0 \mathrm{a}$ & $5.7 \pm 0.1 b$ \\
\hline Day 2 & $5.4 \pm 0.7 a$ & $5.3 \pm 0.6 b$ \\
\hline Day 3 & $5.5 \pm 0.1 \mathrm{a}$ & $4.9 \pm 0.3 b$ \\
\hline Day 4 & $4.7 \pm 0.7 a$ & $4.0 \pm 0.5 b$ \\
\hline \multicolumn{3}{|l|}{ SBW25 vs. FAJ0761 } \\
\hline Day 1 & $5.8 \pm 0.1 \mathrm{a}$ & $5.7 \pm 0.2 b$ \\
\hline Day 2 & $5.4 \pm 0.0 \mathrm{a}$ & $5.0 \pm 0.3 b$ \\
\hline Day 3 & $5.3 \pm 0.0 \mathrm{a}$ & $3.1 \pm 0.2 b$ \\
\hline Day 4 & $4.8 \pm 0.2 \mathrm{a}$ & $3.0 \pm 0.3 b$ \\
\hline \multicolumn{3}{|l|}{ F113 vs. FAJ0758 } \\
\hline Day 1 & $5.8 \pm 0.1 \mathrm{a}$ & $5.6 \pm 0.1 b$ \\
\hline Day 2 & $5.7 \pm 0.1 \mathrm{a}$ & $5.2 \pm 0.3 b$ \\
\hline Day 3 & $5.7 \pm 0.1 \mathrm{a}$ & $4.3 \pm 0.4 b$ \\
\hline Day 4 & $5.4 \pm 0.1 \mathrm{a}$ & $3.3 \pm 0.1 b$ \\
\hline \multicolumn{3}{|c|}{$\begin{array}{l}\text { y In a gnotobiotic sand system. Mutant strains were inoculated on } \\
\text { seedlings in a } 1: 1 \text { ratio with the wild-type strain. } \\
\text { z In every experiment, } 10 \text { plants were inoculated and individually } \\
\text { processed. When values in the same row are followed by a different } \\
\text { letter, they are significantly different at } P=0.05 \text { on nonparametric } \\
\text { multiple comparisons using the Wilcoxon-Mann-Whitney test. }\end{array}$} \\
\hline
\end{tabular}


under vigorous shaking. When indicated, BM was used (Lugtenberg et al. 2001). Medium was solidified with $1.8 \%$ agar (Select Agar; Gibco BRL, Life Technologies, Paisley, U.K.) and when appropriate, kanamycin (Sigma-Aldrich BV, Zwijndrecht, The Netherlands) or 5-bromo-4-chloro-3-indolyl- $\beta$-D-galactoside (X-gal) (SphaeroQ, Leiden, The Netherlands) was added in final concentrations of $50 \mu \mathrm{g} / \mathrm{ml}$ or 40 $\mu \mathrm{g} / \mathrm{ml}$, respectively. Escherichia coli was grown at $37^{\circ} \mathrm{C}$ on solidified LB medium (Sambrook et al. 1989). To determine growth rates of the individual strains, the optical density at $620 \mathrm{~nm}\left(\mathrm{OD}_{620}\right)$ was followed during growth. For growth of wild types and mutants in competition, cultures grown overnight were diluted to an $\mathrm{OD}_{620}$ of 0.1 , and mutant and wild type were mixed in a 1:1 ratio. After growth overnight, the culture was diluted 1,000-fold in fresh $\mathrm{KB}$, samples were diluted and plated on $\mathrm{KB} / \mathrm{X}$-gal, and the ratio between the Tn5lacZ-tagged wild type (blue colonies) and mutant (white colonies) was determined.

\section{Generation of cheA mutants}

via homologous recombination.

Two polymerase chain reaction (PCR) primers (5'-CGCCGATGAAGAAATCCTCCAGGA-3' and 5'-GTCAGCGGCACCTTGATGACGATC-3') were designed on the basis of the $P$. putida cheA (Ditty et al. 1998) and the P. aeruginosa cheA sequences (Kato et al. 1999). For each of the four strains under study, a fragment of the expected length $(1.8 \mathrm{~kb})$ was amplified by PCR using an Eppendorf Mastercycler thermocycler. Lysed colonies were used as a source of template DNA, and $10 \%$ dimethylsulfoxide was added to the reaction mixture to prevent

Table 5. Spatial distribution of WCS365 and its cheA mutant FAJ2060y

\begin{tabular}{lcc}
\hline & & $\begin{array}{c}\text { Competitive root-tip colonization } \\
\text { Competing strains }\end{array}$ \\
\cline { 2 - 3 } WCS365 vs. FAJ2060 & WCS365 & FAJ2060 \\
\hline Part 1 & $6.1 \pm 0.5 \mathrm{a}$ & $4.5 \pm 1.8 \mathrm{~b}$ \\
Part 2 & $5.6 \pm 0.6 \mathrm{a}$ & $3.3 \pm 1.6 \mathrm{~b}$ \\
Part 3 & $5.3 \pm 0.7 \mathrm{a}$ & $2.5 \pm 2.1 \mathrm{~b}$ \\
Part 4 & $4.8 \pm 0.9 \mathrm{a}$ & $2.0 \pm 1.7 \mathrm{~b}$ \\
\hline
\end{tabular}

${ }^{y}$ Competitive tomato-root colonization in a gnotobiotic sand system was tested. Mutant strains are inoculated on seedlings in a 1:1 ratio with the wild-type strain. Plant roots were judged after 7 days. Roots were divided into four parts from crown to root tip: parts 1, 2, and 3 were 2.5 $\mathrm{cm}$ in length and the root tip, part 4,1 to $2 \mathrm{~cm}$.

${ }^{\mathrm{z}}$ In every experiment, 10 plants were inoculated and individually processed. When values in the same row are followed by a different letter, they are significantly different at $P=0.05$ on nonparametric multiple comparisons using the Wilcoxon-Mann-Whitney test. primer mismatching. PCR reaction conditions were: $45 \mathrm{~s}$ at $94^{\circ} \mathrm{C}, 45 \mathrm{~s}$ at $60^{\circ} \mathrm{C}$, and $1 \mathrm{~min}$ at $72^{\circ} \mathrm{C}$.

The respective cheA fragments were purified from agarose gels, cloned with the T/A cloning kit (Invitrogen, Merelbeke, Belgium) in the pCR2.1 vector (Invitrogen), and sequenced on both strands with an automated A.L.F. sequencer (Amersham Pharmacia Biotech, Roosendaal, The Netherlands). These fragments were subsequently cloned in pSUP202, a suicide vector for Pseudomonas strains (Simon et al. 1983). The F113 and SBW25 cheA fragments were BamHI and XhoI digested and then cloned in the pSUP202 BamHI and SalI sites. The OE28.3 and WCS365 cheA fragments were HindIII and XhoI digested and then inserted in the pSUP202 HindIII and SalI sites. In all cases, the pSUP202 SalI site was inactivated, which allowed insertion of the aph-cassette (SalI fragment conferring kanamycin resistance) from pUC4K (Amersham Pharmacia Biotech) in the SalI sites of the cheA fragments from strains F113, SBW25, and WCS365. Due to the presence of two SalI sites in the cheA fragment from strain OE28.3, an internal fragment was replaced with the aph cassette.

The four Pseudomonas strains were transformed with the suicide vector carrying the respective interrupted cheA fragments, and double homologous recombinants were screened by replica plating (loss of the plasmid-encoded chloramphenicol resistance). For strains SBW25 and F113, double homologous recombinants were obtained. The corresponding mutants were designated FAJ0761 and FAJ0758, respectively. The cheA mutants selected for strains OE28.3 (FAJ2061) and WCS365 (FAJ2060) were the result of a single recombination event. Despite repeated attempts, mutants resulting from a double recombination event could not be obtained for these strains. Because an internal cheA fragment lacking the 5' and $3^{\prime}$ parts of the coding region was used for insertion of the aph-cassette, single recombination equally resulted in inactivation of the chromosomal cheA gene.

\section{Motility assays.}

The wild type and cheA mutant strains grown in LB medium until the exponential phase were transferred to $100 \mu \mathrm{l}$ microchambers. Samples of free-swimming cells were inspected with a Nikon Optiphot phase contrast microscope. The images were transferred via a Panasonic Vidicon video camera to a Sony Umatic video recorder. Tracks were analyzed by the Hobson Backtracker image analyzing system (Jeziore-Sassoon et al. 1998).

Motility was also tested as described by Dekkers and associates (1998a). Briefly, KB medium was 20-fold diluted and semisolidified with $0.3 \%$ of agar (Select Agar, Gibco
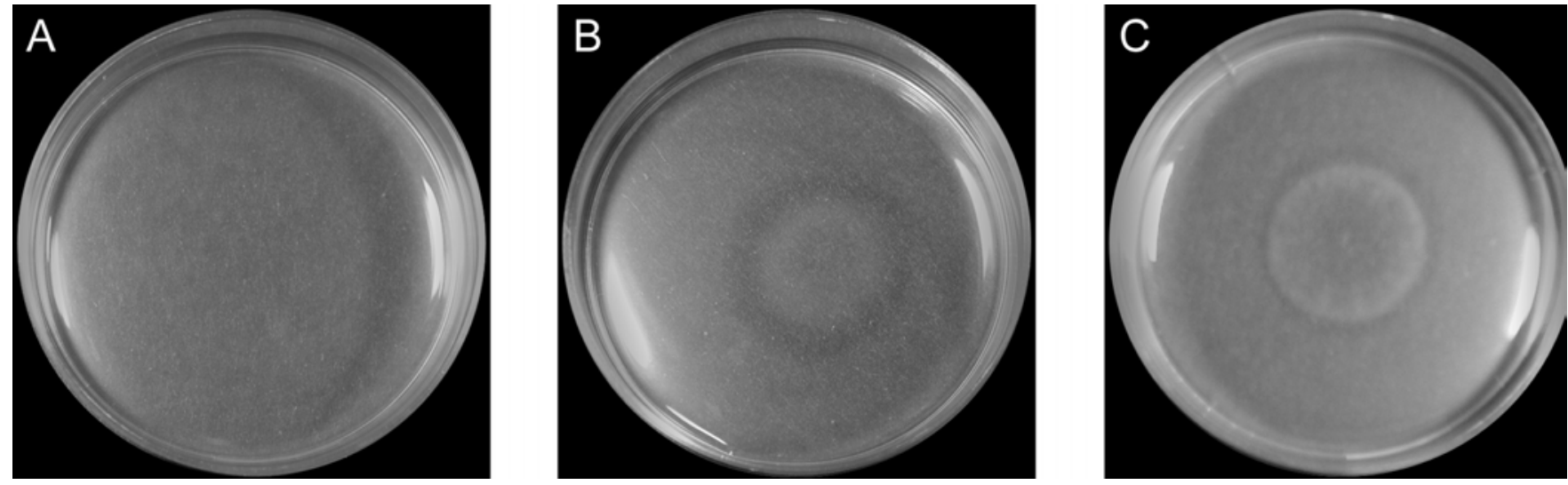

Fig. 2. Chemotactic response of Pseudomonas fluorescens WCS365 to organic acids in a "drop" assay. Drops applied to the center of the dish contained A, chemotaxis buffer; B, $40 \mathrm{mM}$ succinic acid; and C, $100 \mathrm{mM}$ malic acid. Photographs were taken after incubation for $30 \mathrm{~min}$. 
BRL) and poured into petri dishes. Samples of bacteria were applied in the middle of the agar plate, and after growth overnight, the diameter of the resulting spot was measured. Experiments were performed in triplicate. The 20-fold diluted $\mathrm{KB}$ was replaced with BM (Lugtenberg et al. 1999) with succinic acid as the carbon source $(0.01 \%)$ in order to analyze motility under poor nutrient conditions.

\section{Construction of lacZ derivatives of Pseudomonas strains with wild-type colonizing ability.}

Tn5::lacZ insertion mutants were generated by biparental mating of a wild-type Pseudomonas strain (WCS365, OE28.3, or F113) with E. coli S17-1 harboring plasmid pCIB100 (Lam et al. 1990) as described previously by Simons and associates (1996). Tn5LacZ insertion mutants obtained were analyzed for their competitive root-colonizing ability against their wild type in the gnotobiotic system, and appropriate mutants showing wild-type colonization ability were used in the experiments de-

Table 6. Induction of chemotaxis by tomato root exudate and by individual root exudate components ${ }^{\mathrm{x}}$

\begin{tabular}{|c|c|c|c|}
\hline Chemo-attractant & $\begin{array}{l}\text { WCS365 } \\
\text { (wild type) }\end{array}$ & $\begin{array}{c}\text { FAJ2060 } \\
\left(\text { cheA } A^{-}\right)\end{array}$ & $\begin{array}{c}\text { PCL 1524 } \\
\text { (nonmotile) }\end{array}$ \\
\hline Tomato root exudate ${ }^{y}$ & + & - & - \\
\hline \multicolumn{4}{|l|}{ Organic acids } \\
\hline $\begin{array}{l}\text { Malic acid }(10)^{\mathrm{z}}, \\
\text { pyroglutamic acid (20) }\end{array}$ & ++ & - & - \\
\hline $\begin{array}{l}\text { Citric acid (20), succinic } \\
\text { acid (40), fumaric acid (20) }\end{array}$ & + & - & - \\
\hline $\begin{array}{l}\text { Lactic acid, oxalic acid, } t \text { - } \\
\text { aconitic acid, propionic } \\
\text { acid, ketoglutaric acid }\end{array}$ & - & - & - \\
\hline \multicolumn{4}{|l|}{ Sugars } \\
\hline $\begin{array}{l}\text { Glucose, fructose, maltose, } \\
\text { ribose, xylose and sucrose }\end{array}$ & - & - & - \\
\hline \multicolumn{4}{|l|}{ Amino acids } \\
\hline $\begin{array}{l}\text { L-Aspartic acid (9), L-gluta- } \\
\text { mic acid (9), L- isoleucine } \\
(4), \text { L-leucine (8), L-lysine } \\
(20)\end{array}$ & + & - & - \\
\hline
\end{tabular}

${ }^{x}$ Cells were pregrown on semisolid minimal basic medium with $1 \%$ succinic acid. Putative chemo-attractants were tested individually. The response indicated with,+++ , and - refers to a concentration in the 10 $\mu \mathrm{l}$ drop of $100 \mathrm{mM}$. ++ = fast response, after $30 \mathrm{~min} ;+=$ significant response; $-=$ no response.

${ }^{\mathrm{y}}$ Tested at 50 -fold concentrated.

${ }^{\mathrm{z}}$ The lowest concentration $(\mathrm{mM})$ in the $10 \mu \mathrm{l}$ drop that induced a significant response is given in parentheses. All other amino acids detected in the root exudate (Simons et al. 1997) were tested. Except for L-phenylalanine, all amino acids initiated a response from WCS365 cells. scribed here. For Pseudomonas strain SBW25, no lacZ derivative could be obtained with wild-type colonizing ability.

\section{Root-tip colonization assays}

in a gnotobiotic sand system and in soil.

Root colonization assays were performed as described by Simons and associates (1996), using the gnotobiotic system containing sterile sand to which $10 \%$ (vol/wt) plant nutrient solution (PNS) (Hoffland et al. 1989) was added to moisten the sand. This PNS solution does not contain any $\mathrm{C}$ or $\mathrm{N}$ compounds. When colonizing ability in potting soil was tested, the sterile sand column was replaced by nonsterile potting soil (Intratuin, Voorschoten, The Netherlands). For competitive colonization experiments, sterile germinated tomato seeds ( $L y$ copersicon esculentum Mill. cv. Carmello; Novartis Seeds B.V., Enkhuizen, The Netherlands) were inoculated with a 1:1 mixture of a parental strain and tagged with lacZ (except Pseudomonas fluorescens SBW25) and the corresponding mutant strain. The seedlings were placed in the tubes and allowed to grow in a climate-controlled growth chamber at $18^{\circ} \mathrm{C}, 70 \%$ relative humidity, and $16 \mathrm{~h}$ of daylight. After 7 days, roots were isolated, cut into parts that always included the $1-\mathrm{cm}$ long root tip with adhering sand, and bacteria were removed from the root parts by shaking in $1 \mathrm{ml}$ phosphate buffered saline. The ratio between parental and mutant cells was determined by plating dilutions on solidified $\mathrm{KB}$ medium supplemented with kanamycin (only for strains containing a Tn5lacZ or aph cassette) and X-gal (detection limit 100 $\mathrm{CFU} / \mathrm{ml}$ ). For $P$. fluorescens SBW25, plates with and without kanamycin were used to determine the ratio between wild-type cells and cheA mutant cells. When soil columns were used, the plates were supplemented with cycloheximide to a final concentration of $100 \mu \mathrm{g} / \mathrm{ml}$ (Sigma, St Louis) to prevent fungal growth.

All results were statistically analyzed using the nonparametric Wilcoxon-Mann-Whitney test (Sokal and Rohlf 1981). To avoid $\log 0$ cases, calculations were carried out using log $(\mathrm{CFU}+1) / \mathrm{cm}$ root tip.

\section{Isolation of tomato root exudate.}

Tomato root exudate was isolated as described by Simons and associates (1997). Briefly, 100 sterile seedlings were placed in $100 \mathrm{ml}$ of PNS and were allowed to grow in a climate-controlled growth chamber at $18^{\circ} \mathrm{C}, 70 \%$ relative humidity, and $16 \mathrm{~h}$ of daylight. After 7 days, root exudate was collected in $50 \mathrm{ml}$ aliquots and was freeze dried using a freeze-dry apparatus from Snijders Scientific (Tilburg, The Netherlands).
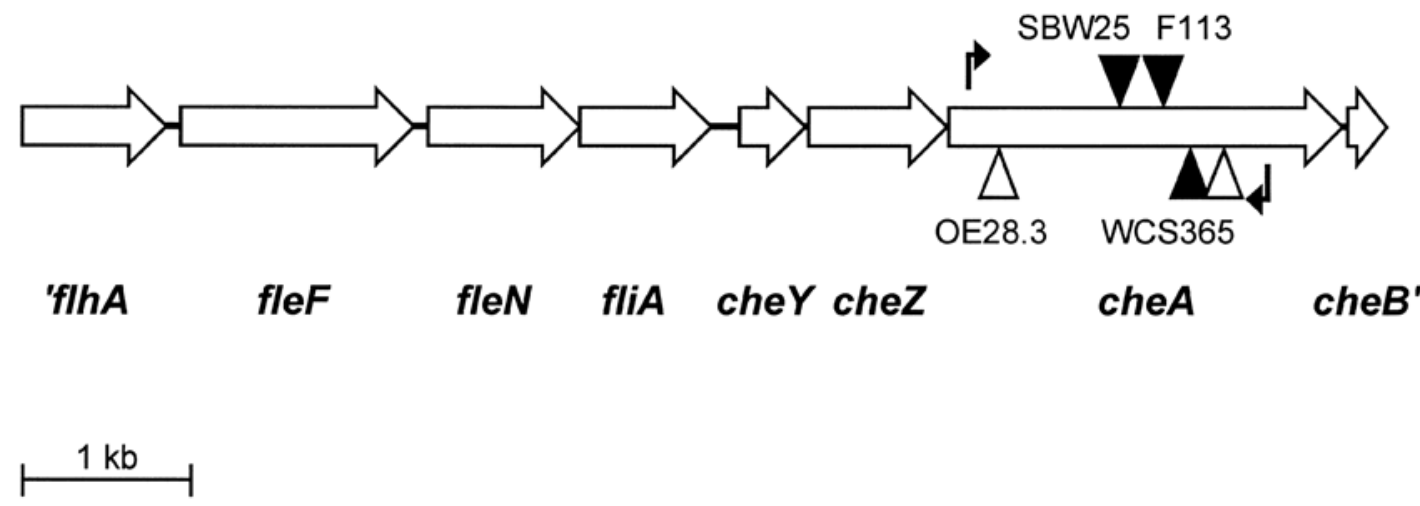

Fig. 3. Organization of the Pseudomonas fluorescens OE28.3 genomic DNA region carrying motility genes ('flhA-fliA) and chemotaxis genes (cheYcheB ). Hooked arrows indicate the position of the primers used to amplify an internal cheA fragment of P. fluorescens OE28.3, F113, SBW25, and WCS365. Labeled arrowheads mark the insertion sites of the kanamycin resistance cassette (aph) in the respective fragments used to construct cheA mutants of strains F113 (same orientation as cheA) and OE28.3, SBW25, and WCS365 (opposite orientation). For strain OE28.3, an internal fragment (bordered by two empty arrowheads) of cheA was replaced with the cassette. 
Root exudate was concentrated by dissolving the obtained freeze-dried material in $1.0 \mathrm{ml}$ of sterile water.

\section{Chemotaxis experiments.}

Chemotaxis experiments were performed using the "drop" assay by Fahrner and associates (1994) as described by Grimm and Harwood (1997) with slight modifications. Briefly, cells grown overnight in $\mathrm{KB}$ were diluted 100 times into $150 \mathrm{ml}$ of $\mathrm{BM}$ containing $1 \%$ succinic acid. When cells reached the early logarithmic phase $\left(\mathrm{OD}_{600}\right.$ of 0.12$), 40-\mathrm{ml}$ samples were resuspended in $12 \mathrm{ml}$ of chemotaxis buffer $(100 \mathrm{mM}$ potassium phosphate [pH 7.0] per $20 \mu \mathrm{M}$ EDTA).

An aqueous solution of $1 \%$ hydroxypropylmethylcellulose (Sigma-Aldrich), formulated to give a viscosity of about 4,000 $\mathrm{cP}$ in a $2 \%$ aqueous solution, was added to the cell suspension to give a final volume of $15 \mathrm{ml}$. The resulting cell suspension was transferred to a 60-mm-diameter petri dish, where it formed an approximately 3-mm-thick layer. Concentrated (50fold) root exudate or individual exudate components (Table 6) (all provided by Sigma-Aldrich) were added to the center of the dish as a $10-\mu$ drop in concentrations of $0.1 \mathrm{M}$ or lower. After incubation for 0.5 to $2 \mathrm{~h}$ at room temperature, the plates were inspected for the appearance of a clear zone surrounding the bacteria attracted to the attractant, which was used as the criterion for a chemotactic response toward the added component.

\section{Isolation of a genomic fragment of $P$. fluorescens OE28.3 containing cheA.}

The 1,800-kb PCR-amplified cheA fragment of strain OE28.3 was used to probe a genomic phage library of strain OE28.3 (De Mot et al. 1992) by plaque hybridization. For the genomic fragment thus isolated, overlapping deletion clones were generated using the EZ::TN Plasmid-Based Deletion Machine (Epicentre Biozym, Landgraaf, The Netherlands) and sequenced using an automated A.L.F. sequencer (Amersham Pharmacia Biotech).

\section{ACKNOWLEDGMENTS}

Parts of the work were supported by the European Union (BIOTECH Project BIO4-CT98-0254) and by a grant from the Vlaams Ministerie van Onderwijs en Vorming (COF/99/002). The authors thank J. Armitage and H. Packer (University of Oxford) for help with the image analysis of motility. Strains SBW25 and F113 were kindly provided by P. Rainey (University of Oxford) and F. O'Gara (National University of Ireland, Cork), respectively.

\section{LITERATURE CITED}

Adler, J. 1969. Chemoreceptors in bacteria. Science. 166:1588-1597.

Aizawa, S., Harwood, C. S., and Kadner, R. J. 2000. Signaling components in bacterial locomotion and sensory reception. J. Bacteriol. 182:1459-1471.

Bourret, R. B., Charon, N. W., Stock, A. M., and West, A. H. 2002. Bright lights, abundant operons-fluorescence and genomic technologies advance studies of bacterial locomotion and signal transduction: Review of the BLAST meeting, January 2001. J. Bacteriol. 184:1-17.

Bull, C. T., Weller, D. M., and Thomashow, L. S. 1991. Relationship between root colonization and suppression of Gaeumannomyces graminis var. triciti by Pseudomonas fluorescens strain 2-79. Phytopathology 81:954-959.

Camacho, M. M. 2001. Molecular characterization of the role of type 4 pili, NDH-I and PyrR in rhizosphere colonization of Pseudomonas fluorescens WCS365. Ph.D. Thesis, Leiden University, The Netherlands.

Chin-A-Woeng, T. F. C., Bloemberg, G. V., Mulders, I. H. M., Dekkers, L. C., and Lugtenberg, B. J. J. 2000. Root colonization by phenazine1-carboxamide-producing bacterium Pseudomonas chlororaphis PCL1391is essential for biocontrol of tomato foot and root rot. Mol. Plant-Microbe Interact. 13:1340-1345.

Darzins, A. 1994. Characterization of a Pseudomonas aeruginosa gene cluster involved in pilus biosynthesis and twitching motility: Sequence similarity to the chemotaxis proteins of enterics and the gliding bacterium Myxococcus xanthus. Mol. Microbiol. 11:137-153.

De Mot, R., and Vanderleyden, J. 1991. Purification of a root-adhesive outer membrane protein of root-colonizing Pseudomonas fluorescens. FEMS (Fed. Eur. Microbiol. Soc.) Microbiol. Lett. 81:323-328.

De Mot, R., Proost, P., Van Damme, J., and Vanderleyden, J. 1992. Homology of the root adhesin of Pseudomonas fluorescens OE28.3 with porin F of P. aeruginosa and P. syringae. Mol. Gen. Genet. 231:489493.

de Weger, L. A., van der Vlugt, C. I., Wijfjes, A. H., Bakker, P. A., Schippers, B., and Lugtenberg, B. J. J. 1987. Flagella of a plant-growthstimulating Pseudomonas fluorescens strain are required for colonization of potato roots. J. Bacteriol. 169:2769-2773.

de Weger, L. A., Kuiper, I., van der Bij, A. J., and Lugtenberg, B. J. J. 1997. Use of a lux-based procedure to rapidly visualize root colonisation by Pseudomonas fluorescens in the wheat rhizosphere. Antonie Van Leeuwenhoek 72:365-372.

Dekkers, L. C., Bloemendaal, C. J. P., de Weger, L. A., Wijffelman, C. A., Spaink, H. P., and Lugtenberg, B. J. J. 1998a. A two-component system plays an important role in the root-colonizing ability of Pseudomonas fluorescens strain WCS365. Mol. Plant-Microbe Interact. 11:45-56.

Dekkers, L. C., van der Bij, A. J. , Mulders, I. H. M., Phoelich, C. C., Wentwoord, R. A. , Glandorf, D. C., Wijffelman, C. A., and Lugtenberg, B. J. J. 1998b. Role of the O-antigen of lipopolysaccharide, and possible roles of growth rate and of NADH:ubiquinone oxidoreductase (nuo) in competitive tomato root-tip colonization by Pseudomonas fluorescens WCS365. Mol. Plant-Microbe Interact. 11:763-771.

Ditty, J. L., Grimm, A. C., and Harwood, C. S. 1998. Identification of a chemotaxis gene region from Pseudomonas putida. FEMS (Fed. Eur. Microbiol. Soc.) Microbiol. Lett. 159:267-273.

Fahrner, K. A., Block, S. M., Krishnaswamy, S., Parkinson, J. S., and Berg, H. C. 1994. A mutant hook-associated protein (HAP3) facilitates torsionally induced transformations of the flagellar filament of Escherichia coli. J. Mol. Biol. 238:173-186.

Geels, F. P., and Schippers, B. 1983. Reduction of yield depressions in high frequency potato cropping soil after seed tuber treatments with antagonistic fluorescent Pseudomonas spp. Phytopathology 108:207214.

Grimm, A. C., and Harwood, C. S. 1997. Chemotaxis of Pseudomonas spp. to the polyaromatic hydrocarbon naphthalene. Appl. Environ. Microbiol. 63:4111-4115.

Hoffland, E., Findenegg, G. R., and Nelemans, J. A. 1989. Solubulization of rock phosphate by rape. Plant Soil 113:161-165.

Howie, W. J., Cook, R. J., and Weller, D. M. 1987. Effects of soil matric potential and cell motility on wheat root colonization by fluorescent pseudomonads suppressive to take-all. Phytopathology 77:286-292.

Jeziore-Sassoon, Y., Hamblin, P. A., Bootle-Wilbraham, C. A., Poole, P. S., Armitage, J. P. 1998. Metabolism is required for chemotaxis to sugars in Rhodobacter sphaeroides. Microbiology 144:229-39.

Kato, J., Nakamura, T., Kuroda, A., and Ohtake, H. 1999. Cloning and characterization of chemotaxis genes in Pseudomonas aeruginosa. Biosci. Biotechnol. Biochem. 63:155-161.

Kearns, D. B., Robinson, J., and Shimkets, L. J. 2001. Pseudomonas aeruginosa exhibits directed twitching motility up phosphatidylethanolamine gradients. J. Bacteriol. 183:763-767.

King, E. O., Ward, M. K., and Raney, D. E. 1954. Two simple media for the demonstration of pyocyanin and fluorescin. J. Lab. Clin. Med. 44:301-307.

Kuiper, I., Bloemberg, G. V. and Lugtenberg, B. J. J. 2001. Selection of a plant-bacterium pair as a novel tool for rhizostimulation of polycyclic aromatic hydrocarbon-degrading bacteria. Mol. Plant-Microbe Interact. 14:1197-1205.

Lam, S. T., Ellis, D. M., and Ligon, J. M. 1990. Genetic approaches for studying rhizosphere colonization. Plant Soil 129:11-18.

Lugtenberg, B. J. J., de Weger, L. A., and Bennett, J. W. 1991. Microbial stimulation of plant growth and protection from disease. Curr. Opin. Biotechnol. 2:457-464.

Lugtenberg, B. J. J., Kravchenko, L. V., and Simons, M. 1999. Tomato seed and root exudate sugars: Composition, utilization by Pseudomonas biocontrol strains and role in rhizosphere colonization. Environ. Microbiol. 1:439-446.

Lugtenberg, B. J. J., Dekkers, L. C., and Bloemberg, G. V. 2001. Molecular determinants of rhizosphere colonization by Pseudomonas. Annu. Rev. Phytopathol. 39:461-490.

Okon, Y., Bloemberg, G. V., and Lugtenberg, B. J. J. 1998. Biotechnology of biofertilization and phytostimulation. Pages 327-350 in: Agricultural Biotechnology. A. Altman, ed. Dekker, New York. 
Rainey, P. B., and Bailey, M. J. 1996. Physical and genetic map of the Pseudomonas fluorescens SBW25 chromosome. Mol. Microbiol. 19:521-533.

Sambrook, J., Fritsch, E. F., and Maniatis, T. A. 1989. Molecular Cloning: A Laboratory Manual. 2nd ed. Cold Spring Harbor Laboratory Press, Cold Spring Harbor, NY, U.S.A.

Scher, F. M., Kloepper, J. W., Singleton, C., Zaleski, I., and Laliberte, M. 1988. Colonization, of soybean roots by Pseudomonas and Serratia species: Relationship to bacterial motility, chemotaxis, and generation time. Phytopathology 78:1055-1059.

Schippers, B., Bakker, A. W., and Bakker, P. A. H. M. 1987. Interactions of deleterious and beneficial rhizosphere microorganisms and the effect of cropping practices. Ann. Rev. Phytopathol. 25 :339-358.

Shanahan, P., O'Sullivan, D. J., Simpson, P., Glennon, J. D., and O'Gara, F. 1992. Isolation of 2,4-diacetylphloroglucinol from a fluorescent pseudomonad and investigations of physiological parameters influencing its production. Appl. Environ. Microbiol. 58:353-358.

Simon, R., Priefer, U., and Pühler, A. 1983. A broad host range mobilization system for in vivo genetic engineering: Transposon mutagenesis in gram-negative bacteria. Biotechnology 1:784-791.

Simons, M., van der Bij, A. J., Brand, J., de Weger, L. A., Wijffelman, C. A., and Lugtenberg, B. J. J. 1996. Gnotobiotic system for studying rhizosphere colonization by plant growth-promoting Pseudomonas bacteria. Mol. Plant-Microbe Interact. 9:600-607.

Simons, M., Permentier, H. P., de Weger, L. A., Wijffelman, C. A., and Lugtenberg, B. J. J. 1997. Amino acid synthesis is necessary for tomato root colonization by Pseudomonas fluorescens strain WCS365. Mol. Plant-Microbe Interact. 10:102-106.

Sokal, R. R., and Rohlf, F. J. 1981. Biometry: The Principles and Practice of Statistics in Biological Research. 2nd ed. W. H. Freeman and Co.
New York.

Stover, C. K., Pham, X. Q., Erwin, A. L., Mizoguchi, S. D., Warrener, P., Hickey, M. J., Brinkman, F. S. L., Hufnagle, W. O., Kowalik D. J, Lagrou, M., Garber, R. L., Goltry, L., Tolentino, E., WestbrockWadman, S., Yuan, Y., Brody, L. L., Coulter, S. N., Folger, K. R., Kas, A., Larbig, K., Lim, R., Smith, K., Spencer, D., Wong, G. K.-S., Wu, Z., Paulsen, I. T., Reizer, J., Saier, M. H., Hancock, R. E. W., Lory, S., and Olson, M. V. 2000. Complete genome sequence of Pseudomonas aeruginosa PAO1, an opportunistic pathogen. Nature 406:959-964.

Suslow, T. V., and Schroth, M. N. 1981. Role of deleterious rhizobacteria as minor pathogens in reducing crop growth. Phytopathology 72:111-115.

van der Bij, A. J., de Weger, L. A., Tucker, W. T., and Lugtenberg, B. J. J. 1996. Plasmid stability in Pseudomonas fluorescens in the rhizosphere. Appl. Environ. Microbiol. 62:1076-1080.

Weller, D. M., and Thomashow, L. S. 1994. Current challenges in introducing beneficial microorganisms into the rhizosphere. Pages 1-17 in: Molecular Ecology of Rhizosphere Organisms. F. O'Gara, D. N Dowling, and B. Boesten, eds. VCH Verlagsgesellschaft $\mathrm{mbH}$, Weinheim, Germany.

\section{AUTHOR-RECOMMENDED INTERNET RESOURCES}

Catholic University of Leuven, Agricultural and Applied Biological Sciences Faculty PGPR and biodegradation web page: http://www.agr.kuleuven.ac.be/dtp/cmpg/research/pgprandbiodegradation.html.

The Department of Energy and University of California Joint Genome Institute website: http:/www.jgi.doe.gov/JGI_microbial/html/index.html.

The Institute for Genomic Research BLAST Search Engine for Unfinished Microbial Genomes web page: http://tigrblast.tigr.org/ufmg/. 